\title{
Real time face recognition of video surveillance system using haar cascade classifier
}

\author{
Adlan Hakim Ahmad', Sharifah Saon², Abd Kadir Mahamad ${ }^{3}$, Cahyo Darujati ${ }^{4}$, Sri Wiwoho \\ Mudjanarko $^{5}$, Supeno Mardi Susiki Nugroho ${ }^{6}$, Mochamad Hariadi ${ }^{7}$ \\ ${ }^{1}$ Independent Researcher, Shah Alam, Selangor, Malaysia \\ ${ }^{2,3}$ Faculty of Electrical and Electronic Engineering, Universiti Tun Hussein Onn Malaysia, Malaysia \\ ${ }^{4,6,7}$ Department of Electrical Engineering, Institut Teknologi Sepuluh Nopember (ITS), Surabaya, Indonesia \\ ${ }^{4,5}$ Narotama University, Surabaya, Jawa Timur 60117, Indonesia
}

\section{Article Info}

\section{Article history:}

Received Jan 30, 2020

Revised Oct 17, 2020

Accepted Nov 29, 2020

\section{Keywords:}

Closed circuit television

Face recognition

Harr cascaded classifier

Raspberry Pi

Surveillance camera

\begin{abstract}
This project investigates the use of face recognition for a surveillance system. The normal video surveillance system uses in closed-circuit television (CCTV) to record video for security purpose. It is used to identify the identity of a person through their appearances on the recorded video, manually. Today's video surveillance camera system usually not occupied with a face recognition system. With some modification, a surveillance camera system can be used as face detection and recognition that can be done in real-time. The proposed system makes use of surveillance camera system that can identify the identity of a person automatically by using face recognition of Haar cascade classifier. The hardware used for this project were Raspberry $\mathrm{Pi}$ as a processor and Pi Camera as a camera module. The development of this project consist of three main phases which were data gathering, training recognizer, and face recognition process. All three phases have been executed using Python programming and OpenCV library, which have been performed in a Raspbian operation system. From the result, the proposed system successfully displays the output result of human face recognition, with facial angle within $\pm 40^{\circ}$, in medium and normal light condition, and within a distance of 0.4 to 1.2 meter. Targeted image are allowed to wear face accessory as long as not covering the face structure. In conclusion, this system considered, can reduce the cost of manpower in order to identify the identity of a person in real time situation.
\end{abstract}

This is an open access article under the CC BY-SA license.

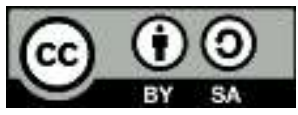

\section{Corresponding Author:}

Sharifah Saon

Faculty of Electrical and Electronic Engineering

University Tun Hussein Onn Malaysia

86400 Parit Raja, Batu Pahat, Johor, Malaysia

Email: kadir@uthm.edu.my

\section{INTRODUCTION}

Video surveillance system is usually work with a surveillance camera to record video for security purpose. The word surveillance is the monitoring of behavior or activities for the purpose of influencing, managing, directing, or protecting people [1-5]. Observation can be done from a distance by means of electronic equipment such as CCTV cameras [6-8] or interception of electronically transmitted information (such as Internet traffic or phone calls). Surveillance camera used to identify the identity of a person through their appearances on the recorded video. This system allows detection and identification of person by recognize its face. By using the proposed system, the identity of a person can be identified in real time. 
Today, there are about 770 million surveillance cameras worldwide with $54 \%$ of these cameras are installed in China and the growth of CCTV has been increased slightly in recent years. In the next three years up to one billion new cameras expected to be installed, due to the deployment of facial recognition system.

Face recognition is one of the interesting and important field of research in past decade. This is due to the need of automatic surveillance system, the design of human computer interface and the interest in human visual system on face recognition. These researches involve knowledge and researchers from difference field such as neuroscience, psychology, computer vision, pattern recognition, image processing, and machine learning [9]. This make the face recognition system become one of the important fields nowaday. The general face recognition structure consist of input image, face detection, feature extraction, and face recognition, verification and identification. However, the main part of this structure are face detection, feature extraction and face recognition.

Face recognition system is being expanding and growing by the researcher all over the world to expand its accuracy and capabilities of this biometric system. This system hold the threat and promise of passive customization and automated surveillance system that enable by face recognition. There are several number of popular algorithm in face recognition including Haar Cascade [2, 10-14], Geometry contour generation and matching $[15,16]$, histograms of oriented gradients [3, 7] back-propagation artificial neural network (BP-ANN) [17] and Convolutional Neural Network [18, 19]. In this project, Haar Cascade, a machine learning for object detection algorithm is used as a face recognition algorithm. The word 'Haar' refer to the mathematic function that related to rectangular shape [15]. It is used to identify object in a video or image [20]. This method has four steps for detecting an object such as Haar-like feature, integral image, AdaBoost learning and Cascade Classifier [21].

For face detection, the Haar feature are the main part of the Haar Cascade Classifier [10, 12, 22]. Haar feature are used to detect the present of feature in the given input image. Each feature gives a single value which calculated by the sum of pixel value under the black rectangle. Haar-like feature offer high speed computing depending on the number of pixels inside the rectangular, and not depending on each pixel value of the image. Obtaining the object detection value, Haar-like feature value is calculated using integral image, that able to calculate value accurate and fast by creating new presentation of image using the value of previous scanned Haar-like feature. In equation (1) and (2), $i(x, y)$ is the value of pixel at $(x, y)$ whereas $I(x, y)$ is the sum of integral of pixel values. The value of integral image, $I(x, y)$ is obtained by sum value of previous index, started by left top until right bottom. Moreover, the summed-area table can be computed efficiently in a single pass over the image, as the value in the summed-area table at $(x, y)$ in the equation.

$$
\begin{aligned}
& I(x, y)=\sum_{\substack{x^{\prime}<x \\
y^{\prime}<y}} i\left(x^{\prime}, y^{\prime}\right) \\
& I(x, y)=i(x, y)+I(x, y-1)+I(x-1, y 1)+I(x-1, y-1)
\end{aligned}
$$

Thus, with some modification on the system, this system expected to be a standalone surveillance system with face recognition that can identify the identity of a person using Raspberry Pi and camera module [21]. This video surveillance system is able to collect and store the data inside the Raspberry Pi memory. Thus, it can reduce the cost of man power to identify the identity of a person in real time. This system is expected to be used for security system such as for security door access and student attendance system.

\section{PROJECT DEVELOPMENT}

Project development for this project consist of three main part which were, data collection, training, and face recognition [3]. This proposed system work once human face was detected, by automatically recognized the identity of a person based on the information of the targeted person. In order, to make this system function properly, the data of targeted person must be collected and recorded into the database. The basic structure of a normal surveillance camera that can detected and recognized physical structure of human face is shown as in Figure 1.

From the first block in Figure 1, video or image of a human face is used as an input to the system. Then, the system captured the targeted person's face to ensure the recognition process can be conducted for further action. The classification and comparison from the image that stored in the database was a part of the recognition process. Once this process completed, the system showed the result of recognized human face. Recognized results showed the match person on the database while, unrecognized result showed as unknown. 


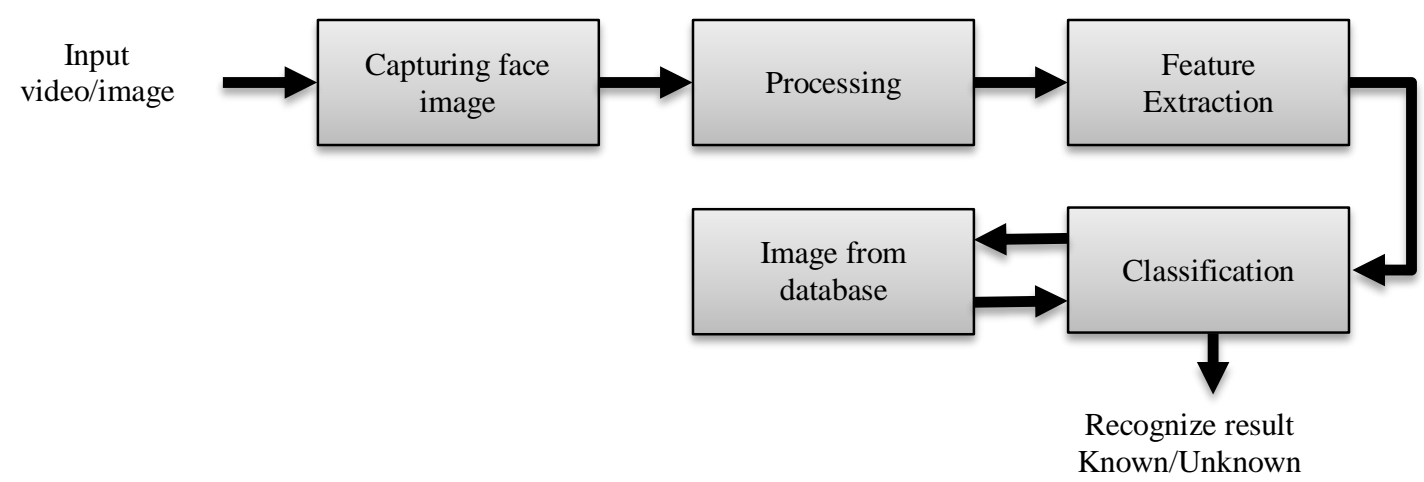

Figure 1. Basic block diagram of face recognition system

Figure 2 shows the overall flowchart of the project development. The project started with gathering information about all the related field regarding face recognition. Then, followed by the setup of the Raspberry Pi workstation with installation of OpenCV library. Once the installation was completed, the OpenCV environment should be tested to ensure its workability. If the OpenCV functional properly and can be run with Python IDLE, the next step was writing the algorithm of recognition using Python code on Raspberry Pi terminal [16, 24, 25]. The code must be synchronized with the OpenCV library and it cascade directory in order to minimize an error messages. Through the recognition code, the data images of a person can be collected using Pi Camera. The data was stored inside the Raspberry Pi memory. The last two steps were to train the recognizer with the data collected and ran the recognition system code to produce the results.

\subsection{Data collection}

In face recognition system phase, the most important task of the system is face detection. While for face detection, the most common way to detect face is using Haar Cascade classifier. It is a machine learning based approach. A cascade function was train from a lot of image and being used for detection. In OpenCV library, it already contain a few pre-training classifier.

Several number of pre-trained cascade classifier are available in the OpenCV library, such as haarcascade_eye.xml, that used for eye detection, and haarcascade_frontalface_default.xml for face detection. For this project, the cascade used was haarcascade_frontalface_default.xml file.

Meanwhile, data collected for this project are image data of human face. The image was converted to a grey scale, because it easy to be processed by the system and low in size thus can saved in Raspberry Pi memory for its database. This system collected only 60 samples of data for each person. The minimum requirement for the system to run face detection is at least 30 images for accuracy of the system. For data collection, it required to run the code of face cascade classifier and start recording face sample using $\mathrm{Pi}$ camera. The code was running a video recording to capture face sample.

\subsection{Train recognizer}

All collected face data are assigned with respective id for the training purpose. Each id was trained as a training and learning process of the recognizer to recognize different id for different persons. To ensure the training process of the collected data able to be run successfully, a specific code and specific folder of the data are required. All data with the given specific id was gathered in one folder named dataset and another folder named trainer need to be created. Inside the trainer folder, there was created file name of trainer.yml for training purpose. This .yml file was required to run the recognition process so that the system was able to recognize the dataset. The system has capability to predict the identity of the detected face based on the id of the dataset.

\subsection{Face Recognition}

A final phase of this project was execution of recognition code in order to execute the face detection and recognition process. As shown in Figure 3, it was an example of multiple face recognition process [14]. All person with a data stored (information) by the system can be recognized. This figure shows, ADLAN and NURDIN were recognize by the system due to matching data in the dataset. While the other person face was not in the database marked as UNKNOWN. 


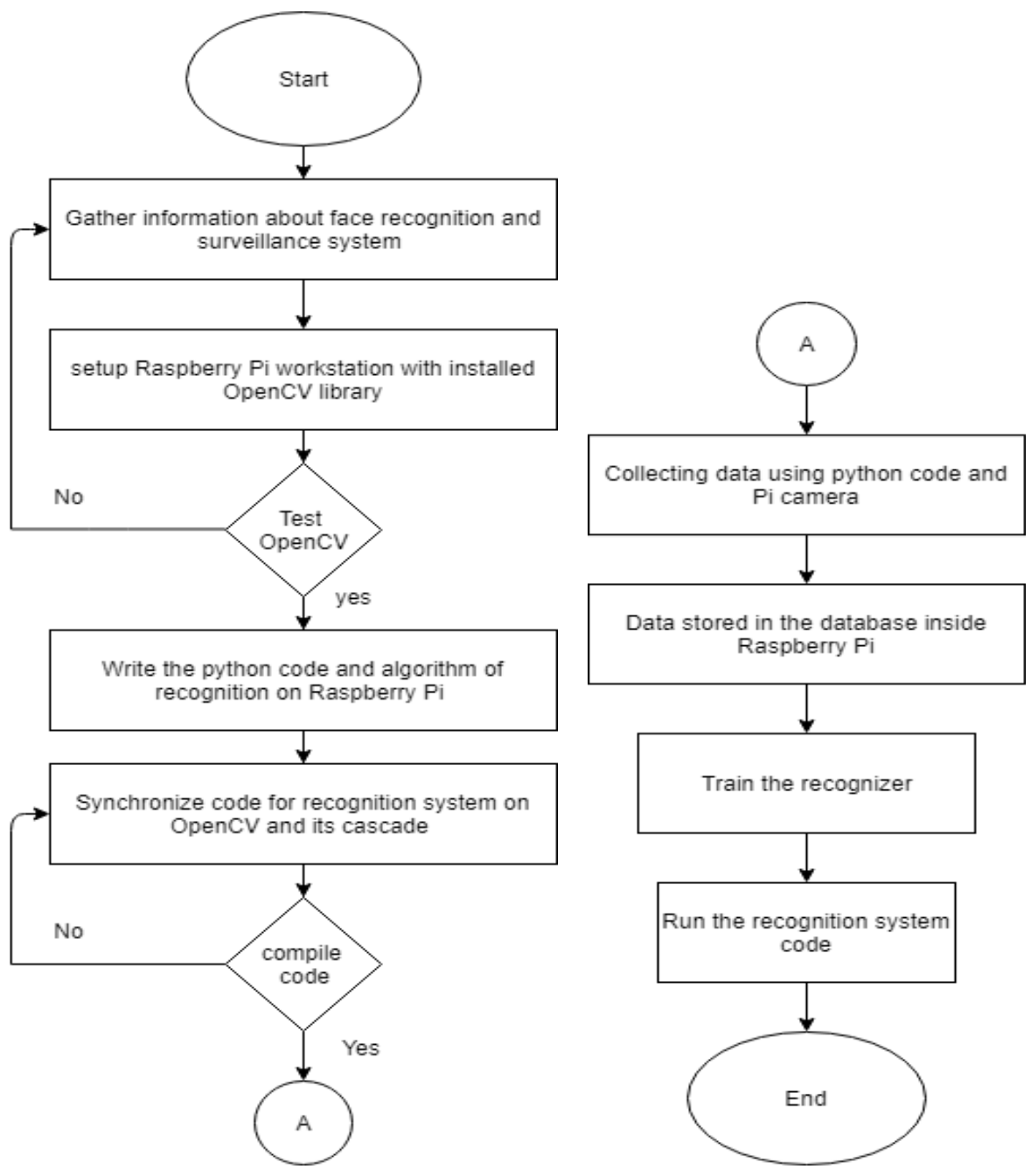

Figure 2. Project Flowchart

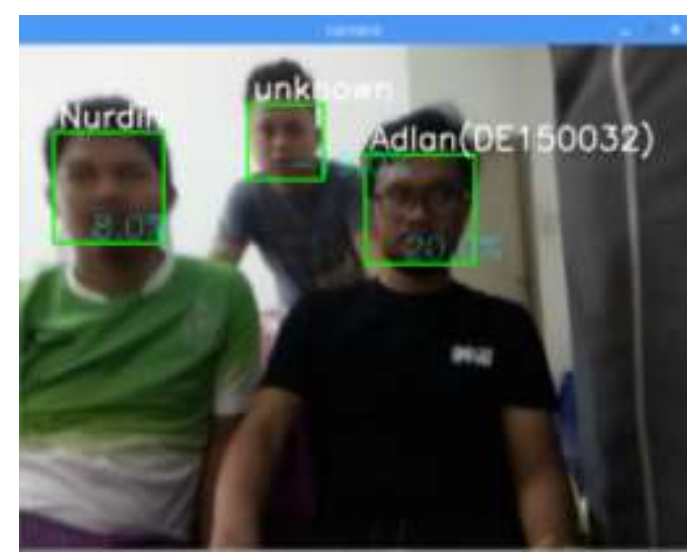

Figure 3. Example of successful face recognition process

Figure 4 shows the Python code needed to be setup in order to identify the person id based on stored data in the database. ADLAN was the first person in the database thus this person was set to hold the first id number. Followed by second, third, fourth and fifth id number, of NORA, NURDIN, FAISAL and IZZAT, respectively. While, Figure 6 was an example of data that have been saved in the database with ADLAN's id. It clearly be seen that; the data was stated with User1.x.jpg due to id number of ADLAN's data. This was the 
specific procedure used in the project to confirm that the system was able to classify different person to be recognize.

On the other hands, this system also tested with difference face angle to ensure the successfulness of the face detection and recognition process. Figure 6 shows the estimation angle of human facing detection and recognition. It was recommended that less than 120-degree angle for human face facing the camera for the face detection system. The green area shows the point of human facing direction considered to be used in this project, while the other angle is considered out of face and difficult to be detected and recognized.

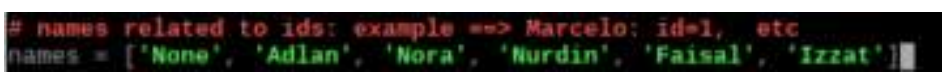

Figure 4. Setting person name

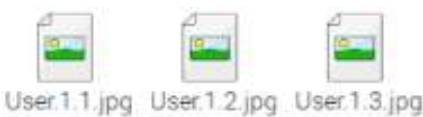

Figure 5. Example id of Adlan's data

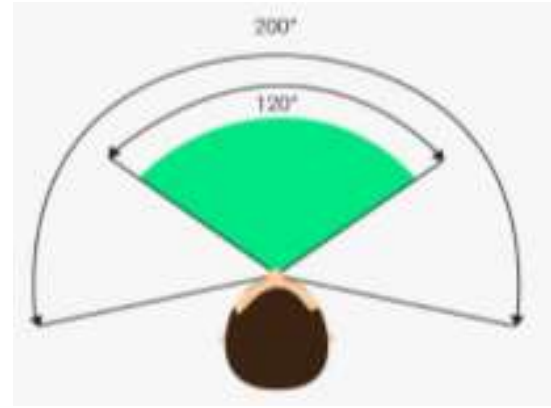

Figure 6. Estimation angle of human facing view

\subsection{Project hardware and software}

This part discussed on the hardware and software that have been used for this project, including the camera module, compiler and libraries. Meanwhile, Raspberry Pi model 3B was used as a main processing unit of the system. Thus, all the hardware and software used must be compatible with Raspberry Pi microprocessor [23, 26]. Captured image done using the camera module of Raspberry Pi, that was design specifically and compatibly with all version of Raspberry Pi including Raspberry Pi 3 B. It has 8 megapixel Sony IMX219 image sensor custom designed add-on board for Raspberry Pi, with capability of 3280 x 2464 pixel of static images that support 1080p30, 720p60 and 640x480p90 video, beside the special features of small in sizes and light weight. In additional this Pi camera can be connected easily to the Raspberry Pi board via a short ribbon cable. With all of this specification, it was the most suitable camera module and affordable to be used in this project.

Python IDLE compiler was used to run the code for this system. It can be run through the Raspberry Pi terminal to make sure this project successfully run with a specific library. While the OpenCV Library that need to be installed with Python IDLE compiler, gave access to run an OpenCV library while using Python IDLE compiler. In this project, Raspberry Pi terminal with the version 3.5.3 Python IDLE compiler and the version 3.3.0 of OpenCV library have been successful installed and ready to be used.

\section{RESULTS AND DISCUSSION}

In this section, project results focus on two parts which, first on the face detection and the second result was on the face recognition. For face detection, the Haar cascade classifier was implemented and running in real time, with the detection result of the person face was displayed automatically as shown in Figure 7. In this process, captured live video was displayed continuously by the system. Once human face was detected and captured by the camera, rectangular box was drawn around the face.

The second result of this project was focusing on the face recognition, which the Pi camera recorded a real time video and the system process the video for face detection and classification of the input video. The input image of the detected face was compared with the set of image in database automatically and the recognition process was executed as shown in Figure 8. As a result, the system displayed the output result of recognition of human face identity. Result displayed the name of the person based on the setting person id at the Python programming code. If the person was not in the database information, the system was not recognized that person and an UNKNOWN information was displayed as shown in Figure 3. Here, two 
person NURDIN and ADLAN were successfully match the face recognition that available in the database system. Thus, system was able to recognize this two faces. Beside that, the project analysis during the development of this project were disscussed, which were, data type used for the system, effect of camera, effect of different angle and variety of face accessories.

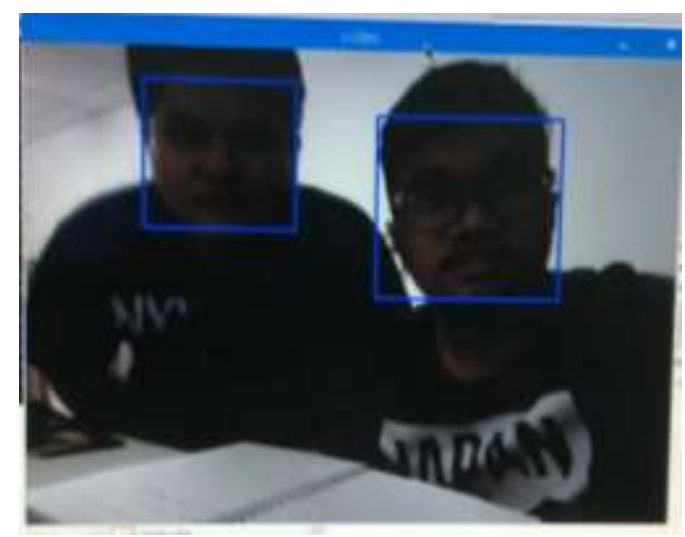

Figure 7. Face detection using Haar Cascade

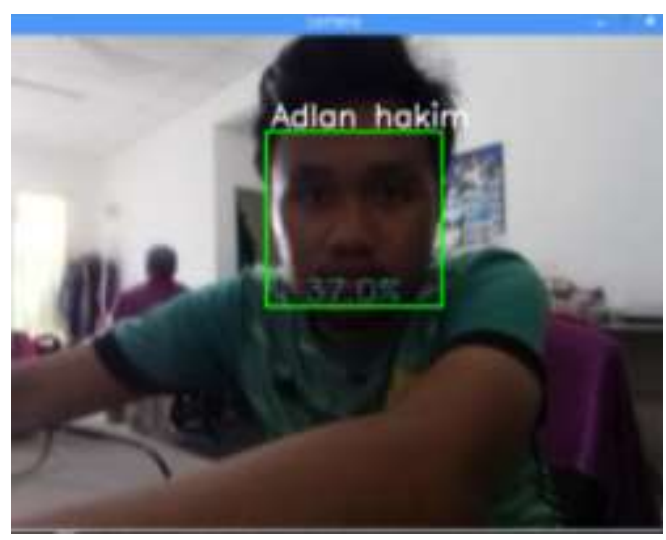

Figure 8. Example of face detection and recognition

\subsection{Data type for the system}

To ensure the system can be run smoothly, data collection was crucial part in this project. As the first feature of the system was face recognition system, the collected data was the image of a person that needed to be stored into database. There are several face impression and style need to be captured and recorded, in order to increase the accuracy of recognition process, with and without an accessories of glasses and hair style, as shown in Figure 9(a).

Besides impressions and facial styles, type of image colour and scale was considered as one of additional features. Thus, gave a versatile and accuracy of the data detection and recognition. Colour scale affected the system performance and should be consider in this recognition process. Figure 9(b) shows the variety of colour mode that can be used in order to create the variety of data. In this project, slate grey image style was considered and used. There were many advantages of using grey scale image, firstly, grey scale image only used two major colour which was black and white, and secondly, binary number of the black and white colour was consider as 1 and 0 , thus system is able to train and run the recognition process easily and completely. Meanwhile, grey scale image also has low size of capacity. Thus give an advantage to the system that work with low memory device, and more data can be captured and stored. For this project, the captured data is stored in the memory of Raspberry Pi, with the size of 32 GB.

In this project, the gray scale data is generated by adding some command in the Python code, in order to convert original image into a gray scale image as shown in Figure 10. While Figure 11, shows collection of variety gray scale image used for the detection and recognition process.
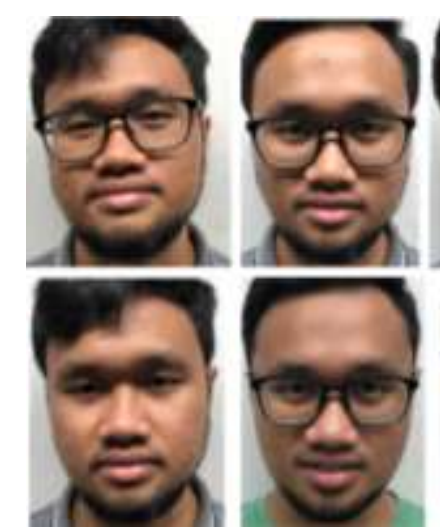

(a)

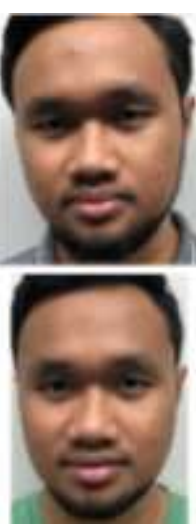

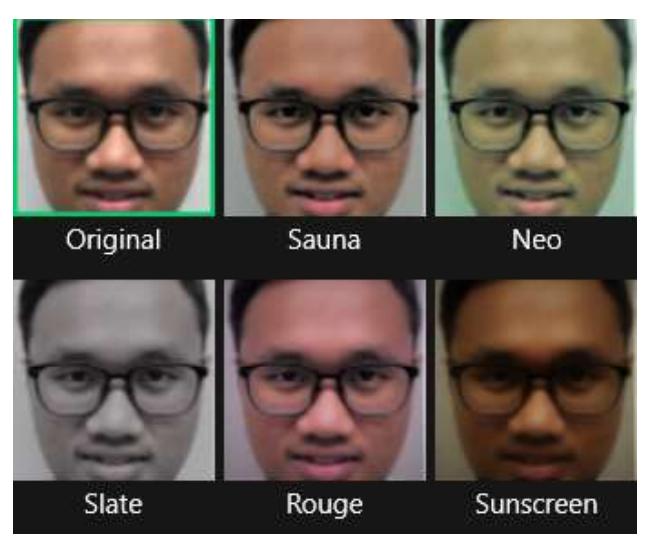

(b)

Figure 9. The variety of (a) face impression and facial style and (b) image colour 


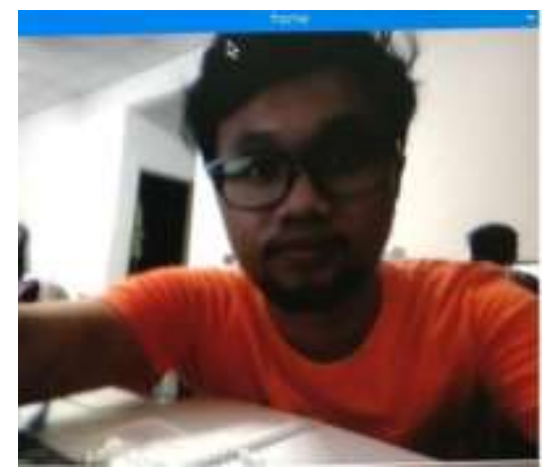

(a)

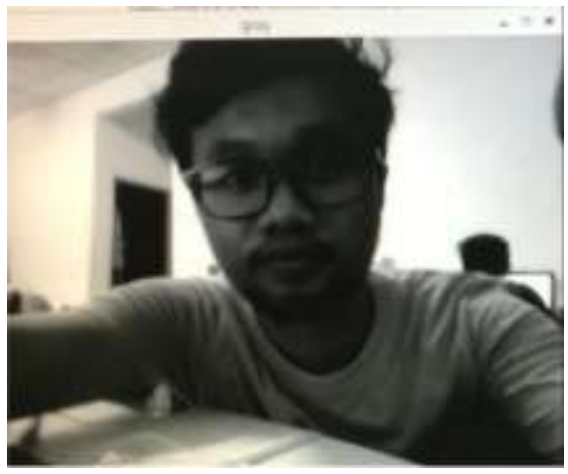

(b)

Figure 10. Example of converting (a) original image to (b) gray scale image

\subsection{Effect of camera}

There were few tests that have been made to the system to discover the accuracy and its limitation. Table 1 shows the data quality taken in low and normal light condition. During low light, it can be said that the face detection was not functioning at all. While in the normal and bright light condition, the detection can be functional normally, as shown in Figure 12. This is due to the specification of Raspberry Pi camera that not suitable to be used in the low light condition.

Table 1. Different of data quality between two light condition

\begin{tabular}{cll}
\hline No & Light Condition & Recognition (\%) \\
\hline 1 & Normal & Recognized (38.0\%) \\
2 & Low & Unrecognized \\
\hline
\end{tabular}
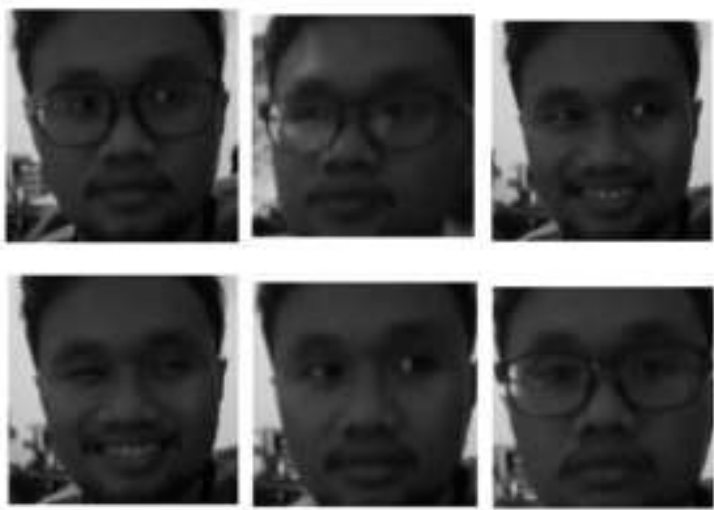

Figure 11. Grey scale image on the database

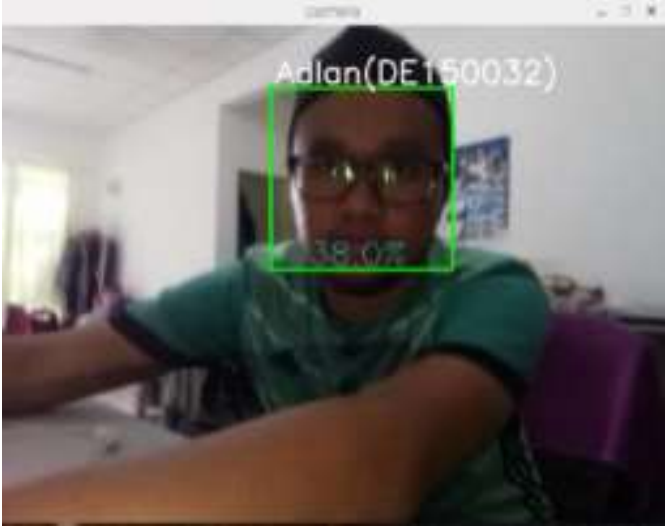

Figure 12. Recognition identity with accessories covering head

\subsection{Face angle}

Experimental testing on the face angle facing the camera was conducted to test on the effect of detection and recognition process, some face angle were shown in Table 2 and Figure 13. Based on Table 2, there are 10 samples of face posing with different angle of face facing to the camera were tested for the detection and recognition. Out of 10 posing with different angle, four angles were suited and can be used for face detection system, and the other testing angles cannot be used for this system. These results show that the detection and recognition face angle were within the angle of $40^{\circ}$, otherwise, it was considered as out of face angle. 


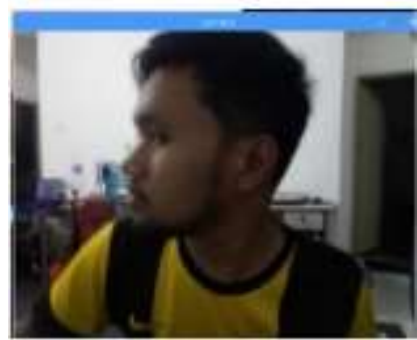

(a)

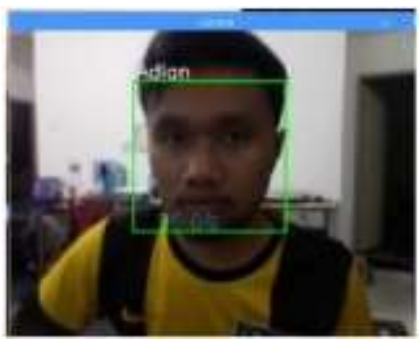

(b)

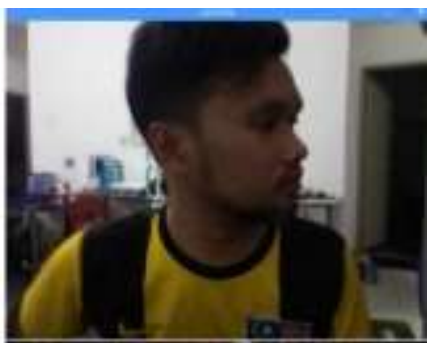

(c)

Figure 13. Face angle of (a) $90^{\circ}$, (b) $0^{\circ}$, and (c) $-90^{\circ}$

\subsection{Effect of face accessories}

Test was continued with the several condition of face with additional accessories and light setting. In this test cases, the image of targeted face was arranged to wear additional accessories such as glasses, sun glasses, hat, and headscarf, as shown in Figure 14. Meanwhile, Table 3 shows the summary of combination tested conditions. Two test results shows unrecognized of face image, which were test number three and eight, due to low in light condition and accessory covering the main facial structure, respectively. As a conclusion, most of the testing condition were able to detect and recognize the face identity, depend on the accessory that putting on the face and light condition as long as it not covering the main structure of the facial; which are face shape, eyes, nose and mouth.

Table 2. Different posture of face angle

\begin{tabular}{ccc}
\hline No & Face Angle & Recognition $(\%)$ \\
\hline 1 & $90^{\circ}$ & Unrecognized \\
2 & $70^{\circ}$ & Unrecognized \\
3 & $50^{\circ}$ & Unrecognized \\
4 & $40^{\circ}$ & Recognized $(39.0 \%)$ \\
5 & $20^{\circ}$ & Recognized (41.0\%) \\
6 & $0^{\circ}$ & Recognized (56.0\%) \\
7 & $-30^{\circ}$ & Recognized (54.0\%) \\
8 & $-50^{\circ}$ & Unrecognized \\
9 & $-60^{\circ}$ & Unrecognized \\
10 & $-90^{\circ}$ & Unrecognized \\
\hline
\end{tabular}

Table 3. Sample result of targeted face with and without accessory

\begin{tabular}{lccc}
\hline No & Light condition & Recognition $(\%)$ & Description of face image \\
\hline 1 & Normal & Recognized (39.0\%) & with glasses \\
2 & Medium & Recognized $(37.0 \%)$ & without glasses \\
3 & Low & Unrecognized & with glasses \\
4 & Normal & Recognized $(53.0 \%)$ & with hair covering part of face \\
5 & Normal & Recognized $(23.0 \%)$ & with sun glasses \\
6 & Medium & Recognized (38.0\%) & with head cover \\
7 & Normal & Recognized (44.0\%) & with hat and covering forehead \\
8 & Normal & Unrecognized & with hat covering forehead and eyes \\
\hline
\end{tabular}

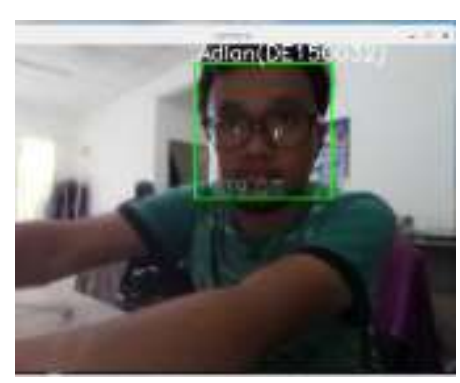

(a)

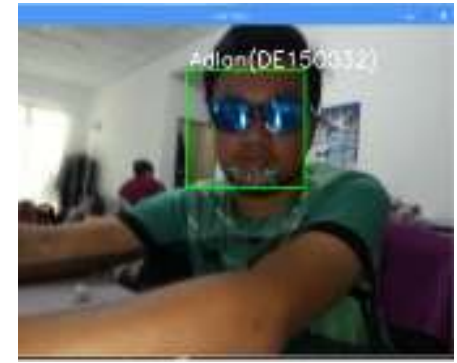

(b)

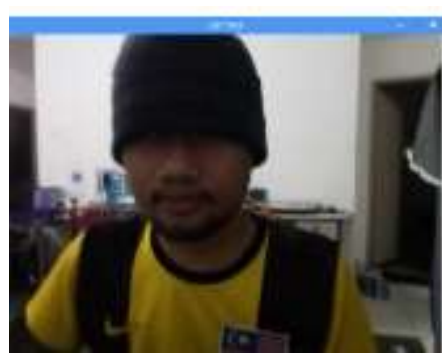

(c)

Figure 14. Sample of image with (a) glasses at normal light condition, (b) sun glasses, and (c) hat covering forehead and eyes 


\subsection{Distance for recognition process}

Meanwhile, this testing was conducted in order to test the maximum distance of the targeted face that can be detected by camera thus recognized by the system. The limitation of the system was depended on the algorithm and the type of camera that been used. Table 4 was summarized the estimated distance for the system that able to recognize the subject. From the table, it clearly be seen that maximum distance of detection and recognition was 1.2 meters and the minimum distance was about 0.3 meters. The captured image is too small to be recognize for the case of distance more than 1.2 meters and too big if distance less than 0.4 meters.

Table 4. Sample of distance test for recognition

\begin{tabular}{ccc}
\hline No & Estimate distance (meter) & Recognition (\%) \\
\hline 1 & 0.4 & Recognized (38.0\%) \\
2 & 0.6 & Recognized (43.0\%) \\
3 & 0.9 & Recognized (39.0\%) \\
4 & 1.2 & Recognized (4.0\%) \\
5 & 1.4 & Unrecognized \\
\hline
\end{tabular}

\section{CONCLUSION}

This project has been conducted successfully, which the software and hardware of the Real Time Recognition of Video Surveillance system was successfully developed. Raspberry Pi that act as the processing unit and Pi Camera Module V2 as a camera module, were installed and the system was able to operate smoothly, which OpenCV library was used as a medium in order to develop a recognition system. The cascade classifier act as a face detection algorithm that was installed together with the OpenCV Library inside the Raspberry Pi system, and Python IDLE was used to execute the program and run all three main phases of recognition system. The system has been tested for the difference light condition, facial expression, accessory and distance to ensure the validity and accuracy of recognition process. Some of the system limitation has been figure out, due to low lightning condition, out of facial angle of $\pm 40^{\circ}$, accessory covering the face structure and the distance out of $0.4 \sim 1.2$ meter. This limitation can be counter in the future using high specification camera module and algorithm. In overall, the proposed surveillance system considered a better system than a normal surveillance system, and expected to be used for security and application system such as in security door access and student attendance system.

\section{ACKNOWLEDGEMENTS}

The financial support received Research Fund E15501, Research Management Centre, Universiti Tun Hussein Onn Malaysia is gratefully acknowledged.

\section{REFERENCES}

[1] B.C. Amanze, et al., "Video Surveillance and Monitoring System for Examination Malpractice in Tertary Institutions" International Journal of Engineering and Computer Science, vol. 5, no. 1, pp. 15560-15571, 2016.

[2] S. Sharma, S. Jain and Khushboo, "A Static Hand Gesture and Face Recognition System for Blind People," 6th International Conference on Signal Processing and Integrated Networks (SPIN), Noida, India, pp. 534-539, 2019.

[3] J. B. Alam, et al., "System Development using Face Recognition," International Conference on Automation, Computational and Technology Management (ICACTM), pp. 408-411, 2019.

[4] Sharmila, "Performance Analysis of Human Face Recognition Techniques," Conference of Internet of Things: Smart Innovation and Usages (IoT-SIU), pp. 1-4, 2019.

[5] Jenif W. S. D’Sauza, et al., "Automated Attendance Marking and Management System by Facial Recognition using Histogram," 5th International Conference on Advanced Computing \& Communication Systems (ICACCS), pp. 66-69, 2019.

[6] E.L. Piza, et al., "Analyzing the Influence of Micro-Level Factors on CCTV Camera Effect" Journal of Quantitative Criminology, vol. 30, no. 2, pp. 237-264, 2014.

[7] R.C. Ng, et al., "Surveillance System with Motion and Face Detection using Histograms of Oriented Gradients", Indonesia Journal of Electrical Engineering and Computer Science, vol. 14, no. 2, pp. 869-876, 2020.

[8] P. Apoorva, et al., "Automated Criminal Identification by Face Recognition using Open Computer Vision Classifiers," 3rd International Conference on Computing Methodologies and Communication (ICCMC), Erode, India, pp. 775-778, 2019.

[9] M. Sundaram and A. Mani, "Face Recognition: Demystificationa on Multifarious Aspect in Evaluation Metrics," pp. 75-81, in "Face Recognition: Semisupervised Classification, Subspace Projection and Evaluation Methods", Dajana Permac, Croatia, 2016. 
[10] A. M. Jagtap, et al., "A Study of LBPH, Eigenface, Fisherface, and Haar-like Features for Face Recognition using OpenCV," International Conference on Intelligent Sustainable Systems (ICISS), pp. 219-224, 2019

[11] T. Dhikhi, et al., "Credit Card Transaction Based on Face Recognition Technology," Journal of Physics: International Conference on Physics and Photonics Processes in Nano Sciences, vol. 1362, pp. 1-8, 2019.

[12] J.J. Hwang, et al., "Faces Recognition Using HAARCASCADE, LBPH, HOG and Linear SVM Object Detector," In: Hwang S., Tan S., Bien F. (eds) Proceedings of the Sixth International Conference on Green and Human Information Technology. ICGHIT Lecture Notes in Electrical Engineering, vol 502. Springer, Singapore, 2018.

[13] S. G. Rabiha, et al., "Face Authentication in E-Learning using Local Binary Pattern and Haar Cascade," 2018 International Seminar on Research of Information Technology and Intelligent Systems (ISRITI), Yogyakarta, Indonesia, pp. 28-32, 2018.

[14] T. Mantoro, M. A. Ayu and Suhendi, "Multi-Faces Recognition Process Using Haar Cascades and Eigenface Methods," 2018 6th International Conference on Multimedia Computing and Systems (ICMCS), Rabat, pp. 1-5, 2018.

[15] T.S. Arulananth, et al., "Human Face Detection and Recognition using Contour Generation and Matching Algorithm" Indonesian Journal of Electrical Engineering and Computer Science, vol. 16, no. 2, pp. 709-714, 2019.

[16] S. S. Hussain and A. S. A. Al-Balushi, "A Real Time Face Emotion Classification and Recognition using Deep Learning Model," Journal of Physics: Conference Series, vol. 1432, pp. 1-13, 2020

[17] M.M. Hussein, et al., "Developed Artificial Neural Network Based Human Face Recognition" Indonesia Journal of Electrical Engineering and Computer Science, vol. 16, no. 3, pp. 1279-1285, 2019.

[18] A. Sarkar, et al., "Society Security System Using Face and Number Plate Recognition," Our Heritage; Special Issue on Multidisciplinary Studies, vol. 68, no. 15, pp. 254-258, 2020.

[19] P. Gupta, et al., "Deep Neural Network for Human Face Recognition," International Journal of Engineering and Manufacturing, vol. 1, pp. 63-71, 2018.

[20] D. Tyas Purwa Hapsari, et al., "Face Detection using Haar Cascade in Difference Illumination," International Seminar on Application for Technology of Information and Communication, pp. 555-559, 2018.

[21] P. Viola and M. Jones, "Rapid object detection using a boosted cascade of simple features," Proceedings of the 2001 IEEE Computer Society Conference on Computer Vision and Pattern Recognition. pp. 511-518, 2001.

[22] P. Apoorva, et al., "Automated Criminal Identification by Face Recognition using Open Computer Vision Classifiers," 3rd International Conference on Computing Methodologies and Communication (ICCMC), Erode, India, pp. 775-778, 2019.

[23] S. Ambre, M. Masurekar, and S. Gaikwad, "Face Recognition using Raspberry PI". In: V. Gunjan, J. Zurada, B. Raman, G. Gangadharan (eds), Modern Approaches in Machine Learning and Cognitive Science: A Walkthrough. Studies in Computational Intelligence, vol 885. Springer, Cham, 2020.

[24] A. Mordvintsev and K. Abid, "OpenCV-Python Tutorials Documentation," OpenCV Python Doc., pp. 1-269, 2017.

[25] M. Khan, et al., "Face Detection and Recognition using OpenCV," International Conference on Computing, Communication, and Intelligent Systems (ICCCIS), pp. 116-119, 2019

[26] Umm-e-Laila, et al., "Comparative Analysis for a Real Time Face Recognition System using Raspberry Pi," IEEE 4th International Conference on Smart Instrumentation, Measurement and Application (ICSIMA), pp. 1-4 2017.

\section{BIOGRAPHIES OF AUTHORS}

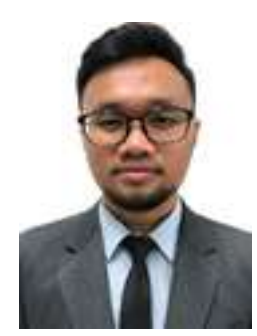

Adlan Hakim Ahmad received his Diploma in Electronic Engineering and Degree in Electronic Engineering form Politeknik Sultan Salahuddin Abdul Aziz Shah, and Universiti Tun Hussein Onn Malaysia, in 2015 and 2019, respectively. Currently he is an Engineer at one of Medical Equipment Distributor Company based in Shah Alam, Selangor, Malaysia. His research interest includes wireless communication, recognition system, and monitoring system.

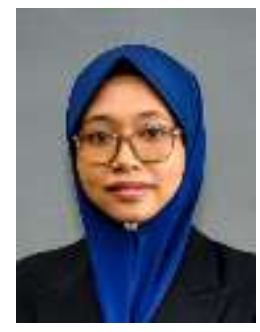

Sharifah Saon is currently a Senior Lecturer in the Faculty of Electrical and Electronic Engineering, Universiti Tun Hussein Onn Malaysia, Malaysia and registered Professional Technologists. She received the Bachelor of Science in Electrical Engineering and Master of Electrical Engineering from Universiti Teknologi Malaysia, and Kolej Universiti Tun Hussein Onn Malaysia, Malaysia, in 2001, and 2004, respectively. Her research interest is in the area of theoretical digital signal processing, visible light communication and digital \& data communication. Including the application to Internet of Things (IoT) and bigdata analysis. She is a member of IEEE, Institute of Engineering Malaysia (IEM), Board of Engineering Malaysia (BEM), and Professional Technologist of Malaysia Board of Technologists (MBOT). 


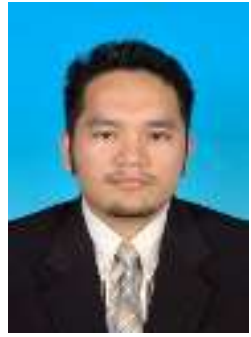

Abd Kadir Mahamad received his Bachelor of Science in Electrical Engineering (2002) and Master of Electrical Engineering (2005) from University Tun Hussein Onn Malaysia before pursuing Doctor of Philosophy (Computer Science and Electrical Engineering) at Kumamoto University, Japan (2010). He currently an Associate Professor at Faculty of Electrical and Electronic Engineering UTHM and registered as Professional Engineer. During the period of May 2015 through May 2016, he was doing industrial attachment at Melaka ICT Holdings Sdn Bhd, as Executive Assistant Manager and was involved in Smart City project in Melaka. He currently leads a research team in Video Analytic and Internet of Things (IoT). His research interests include Deep Learning, Smart City, Intelligent System applications and embedded system. He is also a Senior Member of IEEE, Institute of Engineering Malaysia (IEM) and Board of Engineering Malaysia (BEM).

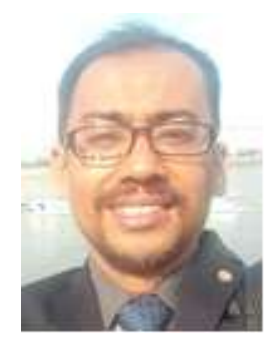

Cahyo Darujati received his Bachelor degree in 2004 and Master degree in 2010 respectively from Electrical Engineering Department, Institut Teknologi Sepuluh Nopember, Surabaya, Indonesia. He is a Professional Lecturer in Faculty of Computer Science, Narotama University, Surabaya, Indonesia and Senior CyberSecurity Consultant for MataElang Project in 2019. His research interest includes computer vision, image and video processing also CyberSecurity. He is IAENG member. (e-mail: cahyo.darujati@narotama.ac.id)

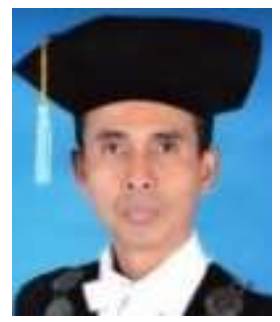

Sri Wiwoho Mudjanarko, born in Surabaya Indonesia, Diploma degree (D3) from Petra Christian University (UK PETRA) Surabaya-Indonesia Teknik Sipil , Bangunan Struktur, Bachelor degree (ST.) from Narotama University Surabaya-Indonesia Teknik Sipil, Perhubungan, Master degree (MT) from Institut Teknologi Sepuluh Nopember (ITS) Surabaya Teknik Sipil, Remote Sensing and Doctor degree (Dr.) from Brawijaya University MalangIndonesia Teknik Sipil, Transportasi. His is lecturer in Civil Engineering Department of Narotama University. Surabaya 60117 Indonesia. (e-mail: sri.wiwoho@ narotama.ac.id)

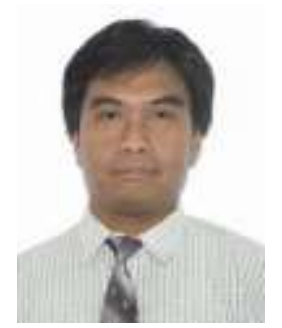

Supeno Mardi Susiki Nugroho graduated from Electrical Engineering Institut Teknologi Sepuluh Nopember (ITS), Surabaya, Indonesia for his bachelor in 1995 and received master and doctoral degree in 2003 and 2013 respectively from Electrical Engineering of Institut Teknologi Sepuluh Nopember (ITS), Surabaya, Indonesia. He is currently a lecturer of Electrical Engineering Department of Faculty of Intelligent Electrical and Informatics Technology Technology from Institut Teknologi Sepuluh Nopember, Surabaya, Indonesia. His research interest includes image processing, computer network, and Artificial Intelligence. (e-mail: mardi@ee.its.ac.id)

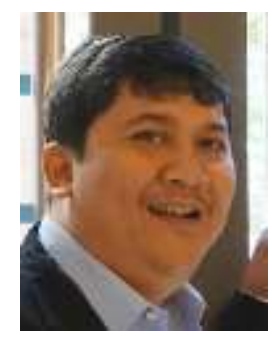

Mochamad Hariadi received the B.E.degree in Electrical Engineering Department of from Institut Teknologi Sepuluh Nopember, Surabaya, Indonesia, in 1995. He received both M.Sc. and Ph.D. degrees in Graduate School of Information Science Tohoku University Japan, in 2003 and 2006 respectively. Currently, he is a staff of the Electrical Engineering Department of Faculty of Intelligent Electrical and Informatics Technology from Institut Teknologi Sepuluh Nopember, Surabaya, Indonesia. He is the project leader in joint research with PREDICT JICA project in Japan. (e-mail: mochar@ee.its.ac.id) 